\title{
Parents' Participation in Cultural Practices With Their Preschoolers ${ }^{1}$
}

\author{
Jonathan Tudge ${ }^{2}$ (The University of North Carolina at Greensboro, USA), \\ Sherrill Hayes, (University of Newcastle, UK), Fabienne Doucet (Harvard University, USA), \\ Dolphine Odero (Egerton University, Kenya), Natasha Kulakova (The Institute of Ethnology and \\ Anthropology, Moscow, Russia), Peeter Tammeveski (The Pennsylvania State University, USA), \\ Marika Meltsas (The University of Tartu, Estonia) and Soeun Lee (Chungbuk National University, Korea)
}

\begin{abstract}
In this article we discuss cross-cultural similarities and variations in parents' engagement in the everyday activities in which their preschool-age children engage, focusing on mothers' and fathers' presence in the same setting as their children, the impact of their presence on the types of activities in which the children engaged, and the extent of mothers' and fathers' involvement with their children in those activities. The data were gathered from different societies the United States, Korea, Russia, Estonia, and Kenya. They reveal that the children were involved primarily in play (more than in lessons, work, or conversation), and this was unaffected by the presence of either parent. However, parents were relatively less likely to be involved in their children's play than in the other activities. Mothers, not surprisingly, were more likely to be found in the same setting as their children and, even when taking account of their greater presence, were more likely to be involved with their children than were fathers.
\end{abstract}

Key words: Culture; social class; preschoolers' activities; parental practices; mothers and fathers.

A few years ago Harkness and Super (1995) argued that everyday, regularly-occurring, activities are important to study both in their own right and as key to understanding what is considered culturally appropriate within any community.

The activities that routinely take place within different settings are key to understanding parents' cultural construction of child life and development. Activities, routines, or cultural practices involved in the care and rearing of children instantiate cultural themes of importance to parents, and in this way they communicate cultural messages. (Harkness \& Super, 1995, p. 226)

It is for this reason that the Whitings and their colleagues (Whiting, 1963; Whiting \& Edwards, 1988) focused exclusively on what people did rather than on what they said or thought to explain the different patterns observed in their Six Cultures study. The term "cultural practice" is related to the concept of "activities" as used by researchers in the sociocultural tradition (Cole, 1995; Miller \& Goodnow, 1995). Those who study practices are primarily interested in what family members $d o$ rather than in what parents say

1 We wish to express our deep appreciation to the parents and children who gave so generously of their time. We also wish to thank the International Research and Exchanges Board (IREX, with funds provided by the U.S. Department of State [Title VIII]), and the Spencer Foundation for grants awarded to the first author, and to the University of North Carolina at Greensboro for the granting of a Kohler Fund Award, Research Assignment, and Excellence Foundation Summer Research Award to the first author. We also thank Sheryl Scrimsher for her helpful feedback on an earlier draft.

2 Address: Correspondence concerning this article should be addressed to Jonathan Tudge. Department of Human Development and Family Studies. The University of North Carolina at Greensboro, Greensboro, NC 27402-6170 - USA. E-mail: jonathan_tudge@uncg.edu in interviews or in response to questionnaires about their children or their approach to parenting. In particular, the study of practices involves a focus on what people do on a regularly-occurring basis. As practices are often repeated they come to be imbued with cultural meaning and value as is clear when one acts in a way different from the norm. Practices are also likely to vary according to parental goals, and this variation is seen most clearly when examining different cultural groups, whose goals for children are determined in part by environmental (LeVine, 1988, 1989) or socioeconomic (Draper \& Harpending, 1987; Whiting \& Whiting, 1975) factors.

In our view, culture consists of a group of people who are viewed by others or who view themselves as constituting a group by virtue of the fact that they share values, beliefs, and practices, who share a similar range of access to resources, and who attempt to pass on those values, beliefs, and practices to the young of the group. This definition allows us to think of cultural groups as being distinguished not only because they are from different societies but as groups that exist within specific societies, by virtue of variations in region, race, ethnicity, or socioeconomic status. It is also important to recognize, echoing Marx, that people are not only the products of culture but its producer. As Youniss (1994) argued:

The position advanced here is not that of a social determinism in which the sociological macrostructure - for instance, social class membership - defines individuals. Social class does not determine rearing practices; only parents do this by weighting options and making choices based on their knowledge. (p. 47)

Our view of the cultural ecology of young children is thus similar to Super and Harkness' (1986) conception of the "developmental niche" (the individual child's cultural 
setting), Weisner's (1984) "ecocultural niche" (family adaptation processes, occurring in cultural settings) and to Cole's (1995) view of "activity."

Given the interrelatedness of cultural context and practices, which change over time, we believe that an appropriate theoretical foundation for any study that seeks to study parenting in context must be one that is systemic and encourages the study of mutual influences of each of these factors. A number of theories satisfy such a requirement, including that of Vygotsky $(1987,1997)$ and Bronfenbrenner (1989, 1993, 1995; Bronfenbrenner \& Ceci, 1994; Bronfenbrenner \& Morris, 1998). Of the two theories, Bronfenbrenner's is easiest to operationalize, and much of Bronfenbrenner's work has been devoted as much to discussions of how to engage in theoretically-appropriate research as to theoretical formulation.

\section{Theoretical framework}

The theory centers around a Process-Person-Context-Time (PPCT) model, of which the first term is the most important (Bronfenbrenner \& Morris, 1998). Proximal processes constitute the "engines of development" (Bronfenbrenner, 1993) and consist of the interactions "between an active, evolving biopsychological human organism and the persons, objects, and symbols in its immediate environment" (Bronfenbrenner, 1995, p. 620). Examples that Bronfenbrenner (1995; Bronfenbrenner \& Morris, 1998) cited include parent-child and child-child activities, group or solitary play, reading, and so on. In other words, proximal processes are the essence of everyday activities in which children are typically involved, often with others. Process in this sense has to do with what occurs in the course of everyday activities on the part of developing individuals and their social partners.

These typically occurring activities are clearly what others have termed practices on the grounds that they constitute the "stuff" of everyday life (Cole, 1995); in the course of children engaging in these activities with others who are more skilled, the children come to understand what is (and what is not) considered appropriate within the particular culture. As discussed earlier, one cannot understand activities or practices without knowing the context within which those activities are carried out. This is true in Bronfenbrenner's theory too.

Bronfenbrenner's $(1989,1995)$ conception of context is broader than most, involving an interconnected layering. At the center is the microsystem - the context in which everyday activities take place in conjunction with the various other social actors who inhabit that context. Microsystems are homes, or classrooms, or groups of friends, or places of worship - anywhere the developing individual spends a good deal of time in face to face interaction with one or more other people, and with the objects and symbols that feature in that context. There is a tendency to focus on development within a single microsystem - on development within the family, or at school, or with the peer group. Bronfenbrenner recognized, however, not only that development takes place in a variety of microsystems, but that interconnections (or the lack of such interconnections) between microsystems also needs to be studied. He termed these types of studies mesosystem analyses.

As mentioned ealier, those who study activities or practices argue that one also needs to understand the cultural context in which these activities take place. Further, activities derive their meaning not so much from the particular microsystems or mesosytems in which they occur as from the broader culture in which those systems are situated. Culture, for Bronfenbrenner (1993), is defined as a macrosystem, a group of people who share values and beliefs, as well as "resources, hazards, lifestyles, opportunity structures, life course options and patterns of social interchange" (p. 25). By this definition, culture can be considered both at the societal level (as in the cultural groups studied by most cross-cultural researchers) and when examining different within-society cultural groups. Such groups may differ by race, ethnicity, region, or on socioeconomic grounds.

Although it is clearly necessary to study activities in context, Bronfenbrenner (1995; Bronfenbrenner \& Morris, 1998) has argued that one must also understand what the participating individuals bring to the activities in which they engage. Parents' decisions to encourage their children to participate in certain types of activities and to discourage them from participating in others stems in part from their values for their children (the qualities they wish their children to have) and their beliefs about how to bring those values into reality. Where do these values and beliefs come from? As cultural anthropologists would argue, they must be considered a cultural phenomenon, for cultures are marked by the fact that members of a cultural group share values that distinguish them from other cultural groups. The expression of those values occurs, of course, while engaging in activities within microsystems. As Cole (1985) argued about Vygotsky's concept of the zone of proximal development, the expression of parents' values as they engage in activities with their children is the crucible in which culture and development occur.

For Bronfenbrenner (1989, 1993), although values and beliefs are important, they are not the only important factor when considering what the individual brings to bear. For example, although studies of socialization often focus on what parents do to their children, it is also necessary to consider the fact that children influence their own environments (for example, by initiating new activities, drawing others into their activities) while at the same time being influenced by those around them. Thus, at the level of the person, Bronfenbrenner wrote about the "developmentallyinstigative" characteristics of individuals, such as their directive beliefs, their activity level, their temperament, and their goals and motivations. All of these have an impact on the way in which the context is experienced by the developing individual as well as the types of contexts to which the individual is drawn. It is also important to consider "personal stimulus" characteristics, such as gender, that have 
an influence on the ways in which other people deal with the developing individual and the goals, values, and expectations they have for that individual.

The final element in Bronfenbrenner's model is time, a recognition not only that to study development means to examine it over time (necessitating longitudinal research) but that we must always consider the developing system within its historical context. In our research we have explicitly tried to use Bronfenbrenner's ecological theory as the foundation for the methods we have used and for the types of variables we have considered important to include in our measures. In this paper, however, we are going to concentrate on proximal processes in different macrosystems, with macrosystem being considered at both the societal and socioeconomic levels, focusing on parents' extent of involvement with their children in the various activities in which the children are engaged.

\section{The Role of Mothers and Fathers}

Why focus on parents? We do not wish to suggest that the only people who are important in a child's life are his or her biological parents - siblings, teachers, extended family members, and peers all may play large roles (Howes \& Clements, 1994; Howes \& Tonyan, 1999; Taylor, Jackson, \& Chatters, 1997; Tobin, Wu, \& Davidson, 1989; Wakschlag \& Chase-Lansdale, 1996; Weisner, 1987). However, as Bronfenbrenner and Morris (1998) argued: "The principal persons with whom young children interact 'on a fairly regular basis over extended periods of time' are parents" ( $p$. 997). Moreover, there has been a growing interest over the past 20 years regarding the extent to which fathers are involved with their young children (Lamb, 1997). Our data allow us to examine the extent to which mothers and fathers are both available to and engaged with their young children, and we are able to do this while examining the everyday activities in which children are involved in a variety of different cultural groups.

Lamb and his colleagues (Lamb, Pleck, \& Levine, 1985; Marsiglio, Day, \& Lamb, 1997) argued that parents' involvement with their children can be differentiated as engagement, accessibility, and responsibility. Engagement involves direct caregiving, assistance, playing with, or talking to the child, accessibility (or availability) means simply being in the same location as the child and thus being potentially available to the child, and responsibility has to do with knowing what the child needs and making decisions on behalf of the child. Determining levels of responsibility is a difficult task, and thus the majority of research has focused on engagement or availability (Doherty, Kouneski, \& Erickson, 1998).

"Use of time", diary, and observational studies reveal that fathers typically, in many industrialized nations at least, are available to their children far less frequently than are mothers, and engaged with their children even less (Lamb, 1987; Lewis, 1997; McBride \& Mills, 1993; Pleck, 1997). Much of this research relies on self reports from the parents (often only from the mothers), with observational data collected in laboratories more often than in a naturalistic setting, at least in the United States (Dessen \& Lewis, 1998; Mackey, 1996; Volling \& Belsky, 1991). In the culturalanthropological literature, by contrast, the research relies far more on observations in natural settings. For example, in their report of the cross-cultural "Six Cultures" research, Whiting and Edwards (1988) showed that mothers were about twice as often available as were fathers, although the amount of cultural variability was high, with Indian and Kenyan fathers almost never involved with their young children whereas involvement was much greater in Mexico, the Philippines, and Okinawa.

Fathering may be viewed by many as a "secondary activity" (Lewis, 1997) when one compares the amount of time that mothers and fathers spend caring for children, but there is little compelling evidence that what mothers and fathers do with their preschool-age children is very different, even though there is wide individual variation among fathers in the extent of their engagement (Lewis \& Dessen, 1999). However, according to Lewis, scholars continue to assume that fathers are more likely to engage in rough and tumble play with their children and that they treat boys and girls differently, with presumed implications for sex-role development.

In this project we made extensive observations of children in their everyday settings, and so are able to examine the different types of activities in which they engage. We are also able to examine mothers' and fathers' availability to and involvement with their children in these activities and can study this in a variety of different societies and, within societies, social class groups. We are thus able to examine the extent to which mothers' or fathers' availability changes the types of activities in which children engage and the types of activities in which mothers and fathers actually engage with their children.

\section{Methods}

\section{Participants}

The societies in which we gathered the data are very different from one another - the United States, Korea, Russia, Estonia, and Kenya. What we wanted to do was to keep some things as similar as possible, so that differences in our results could not be confounded by rural-urban differences, or size of city, or social class mix. We therefore chose a single city from each society, one that is medium-sized with a range of cultural and educational amenities and a population mix that includes both families who are well educated by the standards of the society and whose occupations are professional and families who have less education and whose jobs are within the blue-collar or working class domain. For ease of discussion, these families will be referred to as "middle class" and "working class", respectively. In each case two small areas of the city were chosen, and we tried to recruit as participants all the families who had a child between the ages of 28 and 50 months. Our goal was to study families that were typical in the particu- 
lar communities chosen. We therefore did not include or exclude families on the basis of family structure (single or two-parent families), number of siblings, presence of extended family members, etc.

Greensboro, NC, USA. This city consists of about 200,000 inhabitants, located approximately 250 miles $(400 \mathrm{~km})$ south of Washington, DC. Participants were recruited from birth records if they lived in one of two areas (each 2-3 square kilometers) judged to be relatively homogeneous in terms of housing and racial (European-American) background. A total of 20 families with young children participated from these two communities (one middle class, the other working class). Acceptance rates from those initially contacted were quite high (64\% and $78 \%$ in the middle class and working class communities), and the two groups of families which participated consisted of 11 middle class families and nine working class families with children aged from 30-48 months. The families were clearly differentiated by education (no working class parent had a college degree whereas virtually all middle class parents had at least a degree) and occupation criteria, using Hollingshead (1975) rankings.

Suwon, South Korea. This town of about 700,000 inhabitants is located approximately 70 kilometers from Seoul, and is one of the satellite cities around the capital, with a branch of Seoul National University situated there. Two communities were selected; in one lived families who were mostly well educated (most of whom had at least a college degree) and in which the fathers had professional occupations, whereas in the other lived primarily working class parents, none of whom had completed a college education. Inspection of birth records was not possible in Suwon, and community representatives helped us to locate potential participants. Families had to meet the same educational and occupational criteria as was the case in Greensboro. Twelve families participated in Suwon, divided equally by community and gender. However, recruitment was far more difficult in Suwon than in the other cities. Of 36 families who were contacted in the middle class community, 13 (36\%) were willing to participate, but seven of the children were enrolled in preschools that did not permit observations. In the working class community, 16 families were contacted, of whom seven $(44 \%)$ were willing to participate, but one was enrolled in a preschool that did not permit observations (Tudge, Hogan, Lee, et al., 1999). The clearly lower acceptance rates in Suwon are most likely related to the fact that mothers almost exclusively look after their children while young, and Korean families are less willing to have strangers enter the home.

Obninsk, Russia. This town is situated about 100 kilometers south of Moscow, and has approximately 120,000 inhabitants. As is true of all cities in the former Soviet Union, it was not possible to find areas of the city that were differentiated by social class, type of occupation, and so on. Well educated professional families are likely to live next door to less educated workers. Inspection of birth records was not possible, so we used initial contacts to recruit via a "snowball" technique. Half of the 12 Russian families who participated consisted of parents who had the equivalent of a US college education or higher and whose primary occupation was judged to be professional (many parents held more than one job, as a way of supplementing their income). The other half had no more than the equivalent of high school in the United States and worked in the non-professional sphere. In other respects, these two groups of families were quite similar. For example, they lived in very similar apartment complexes in the same areas of town, and incomes were also similar. It is thus clear that, although in terms of education and occupation the two groups in Russia differed greatly from each other, in terms of income and housing the two groups of Russian families did not differ at all. This was in marked contrast to the groups of US, Kenyan, and Korean families (Tudge, Hogan, Lee, Meltsas, Tammeveski, Kulakova, Snezhkova, \& Putnam, 1999).

Tartu, Estonia. This city, of approximately 100,000 inhabitants, is located 180 kilometers south of Tallinn, the capital of Estonia. As was the case in Greensboro, two areas of the city were selected, one of which consists solely of apartment complexes and the other from an area of singlefamily houses, both new and old. Each area is smaller than its Greensboro equivalents, approximately 1 square kilometer, but with a similar or higher density of families. Each area was bounded by large roads or by the river. Families were located from the birth records, as was the case in Greensboro. Workers at the local ministry supplied names and addresses and occasionally some basic demographic details (such as educational level) of families living in the relevant streets and with children of the approximate age. Of the 34 families who were contacted, $67 \%$ agreed to participate, from which 20 families were selected, equally divided by social class. As was the case in Obninsky, the families were clearly differentiated by educational level and by occupational status, but were not differentiated by income or neighborhood (Tudge, Hogan, Lee, et al., 1999).

Kisumu, Kenia. This city, located approximately 500 kilometers west of Nairobi, the capital, has about 300,000 inhabitants. Residential houses and apartments are organized into estates that range in size from 0.5 to 1 square kilometer and are clearly distinguished by quality of housing, such that some estates are home to middle class families and others to working class families. Twenty families participated, evenly divided by social class. All participants were Luo, the second largest ethnic group in Kenya and the largest group in Kisumu. All but two working class families were monogamous; the two polygamous fathers divided their time between their wives' households. Children were located partly from birth records (six of nine middle class families agreed to participate and all five working class families) and the remainder from snowballing as too few children of the requisite age had been located. Families were recruited from three middle class estates and two working class estates, and they were clearly distinguished in terms both of education and occupation (Odero, 1998). 


\section{Observations}

Families were asked to keep their daily routines unchanged as much as possible during the observation period. Each child (aged between 28 and 50 months) was observed, wherever he or she was, for 20 hours over the course of a week to capture the equivalent of an entire waking day. We thought it important to observe for the full day, in order to discover the range of activities in which these children engaged and the range of settings in which they were placed. We also wanted to limit the likelihood that the participants would change their behavior, something more likely to occur during short-lived observations (Tudge, Hogan, \& Etz, 1999). Observations were continuous in 2- and 4-hour blocks, but activities were only coded during 30-second "windows" every $5 \frac{1}{2}$ minutes, using modified spot observations (Tudge, Sidden, \& Putnam, 1990). During any 30-second window, more than one activity could occur and could be coded. All observers were from the cultural group being observed, and were trained to reliability by the first author.

Activities were coded as being "available to" the child if they occurred within his or her ear- or eye-shot. Children were coded as being "involved in" the activities if they were physically participating or were observing. As well as observing which activities were available to the child and which he or she became involved in, we coded how activities were initiated and by whom, the manner in which the child became involved in any activity, any partners in activity, their respective roles, and so on. These analyses are based on approximately 180 observations for each child and do not include the final two hours of observation which were videotaped.

The activities in which we were interested were lessons (4 categories), work (5 categories), play, exploration, and entertainment (10 categories), conversation (3 categories), and "other" ( 6 categories, including sleeping, eating, etc. $)^{3}$. In brief, lessons were defined as involving the deliberate attempt to impart or receive information in four areas: academic (spelling, counting, learning shapes and colors, etc.); interpersonal (teaching etiquette or "proper" behavior); skill/ nature (how things work, why things happen); and religious lessons. Work was defined as "activities that either have economic importance or contribute to the maintenance of life" (Tudge et al., 1990) and was broken down into work involving no technology, clear technology (such as sweeping with a broom), or more complex technology (such as using a vacuum cleaner). Play (including exploration and entertainment) was defined as activities that were being engaged in for fun or for their own sake, with no apparent curriculum (which would constitute a lesson) or sense that the activity had economic importance (work). Types of play included pretend/role play, play with an academic object (such as looking at a book), playing with objects typically designed for children, playing with adult objects, other types

3 For full details of the coding scheme, please refer to Tudge et al, 1990. of play (such as chase or rough and tumble), and watching television. Thus a child looking at a book or being read to would be coded as engaging in "play with an academic object" whereas the child asking what a particular word was, or being asked to name the colors would be coded as being involved in an academic lesson. Conversation was defined as talk that was not related to the on-going activity and had a sustained or focused topic. Talking that was an integral part of play, work, or a lesson was therefore not coded as conversation, but if children talked about some other activity or an earlier bout of play, while engaging in play, would be coded as engaging in both play and conversation.

We were also interested in the partners, if any, who were engaged with the children in the activities in which they were involved. The level of engagement varied from doing the activity with the child, with all participants taking a more or less equal role in it, to one person watching another who was more actively involved. In the latter case, we coded someone as a partner whether that person was observing the child (who was more actively engaged) or being observed by the child. For the most part, however, partners were actively involved with the child in an activity. Multiple partners could be coded as being engaged in any one activity with the child. If the child was not involved in an on-going activity by definition he or she could have no partner. We were also interested in knowing whether the child's mother and/or father were in the setting with the child, irrespective of whether she or he were partnering the child in an activity. If they were present in the setting they were coded as being "available" to the child.

\section{Results}

Where were these children situated? Not surprisingly, and as displayed in Figure 1, for most of our observations they were in or around the home. Expressed in percentages, to account for variations in observations in which the location was recorded (ranging from 160 to 200), the children were at home from a low of about $2 / 3$ of the time for the Greensboro White middle class children to over $80 \%$ of the time, in the case of the Tartu middle class children and in the case of the Kisumu working class children. The children

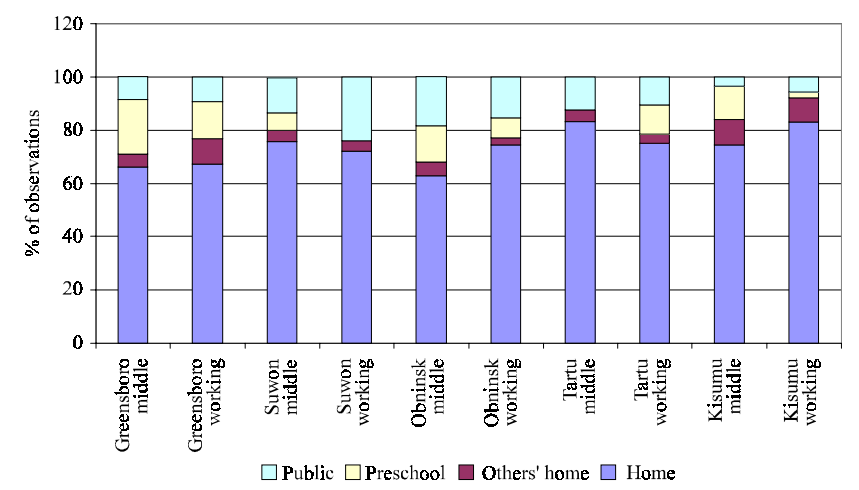

Figure 1. Where the children were situated according to cultural groups. 
were least likely to have been found in other people's homes, ranging from $2.6 \%$ of the observations among the Obninsk middle class children to $9.5 \%$ for the working class White Greensboro children.

The data were far more variable in the case of being observed in some type of formal preschool setting or in a public space (such as a park, or at a shop or library). The Suwon working class children, Tartu middle class children, and children from the Kisumu working class backgrounds were never or rarely observed in preschool. Children from Greensboro, particularly those from middle class families, were most likely to spend time in some type of preschool or other formal child-care setting. The situation was also quite variable with regard to observations in public spaces. Suwon and Obninsk children were more likely to be situated in a public space (shopping or in a park) than were the Greensboro and Tartu children, and the Kisumu children least likely of all.

The activities in which the children were engaged have been discussed in more detail in earlier publications (Tudge \& Putnam, 1997; Tudge, Doucet, Odero, Tammeveski, Lee, Meltsas, \& Kulokova, 1999; Tudge, Hogan, Lee, et al., 1999). In brief, however, and as displayed in Figure 2, the children in each group were far more likely to be found in play than in any other activity, followed by work, conversation, and lessons. Because the number of observations varied somewhat we have expressed the data as percentages of observations (the percentages do not sum to 100 because we have not included in these analyses the cases in which the children were involved in the "other" category). The observations of play ranged from a low of $45 \%$ among the Greensboro middle class children to a high of over $73 \%$ for the working class Suwon children. Obninsk and Tartu children were more likely to be involved in lessons than were children from the other cities, but it is also worth noting that middle class children in each city were more likely to be involved in lessons than were their working class counterparts. The same was true with regard to conversation middle class children were consistently more likely to be involved in conversation than were working class children. By contrast, working class children were more likely to be

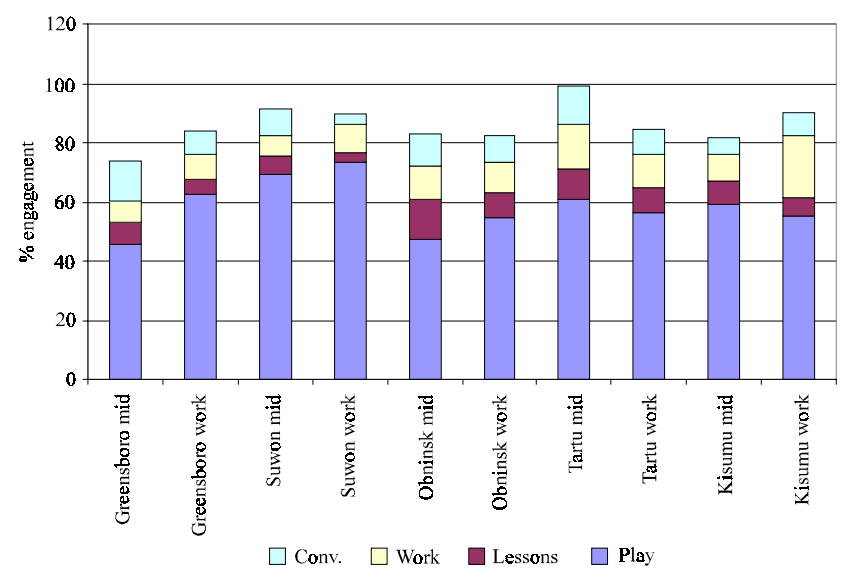

Figure 2. Children's engagement in activities according to cultural groups.

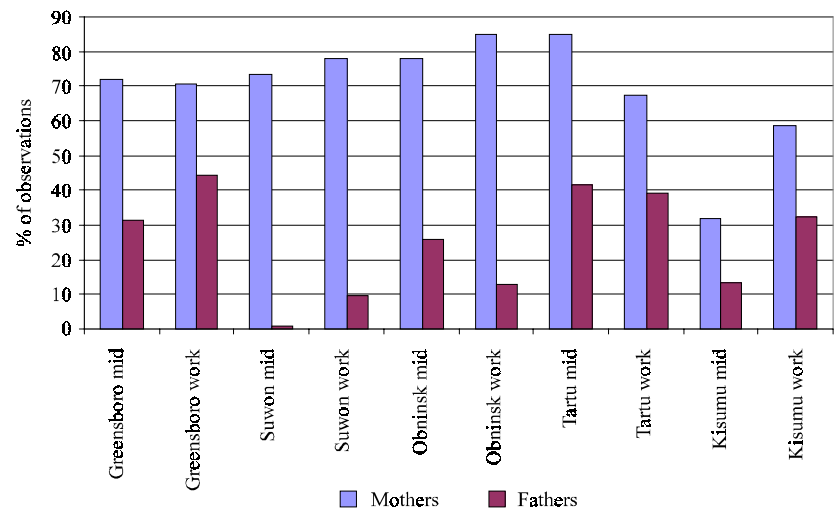

Figure 3. Parents in the same setting as children according to cultural groups.

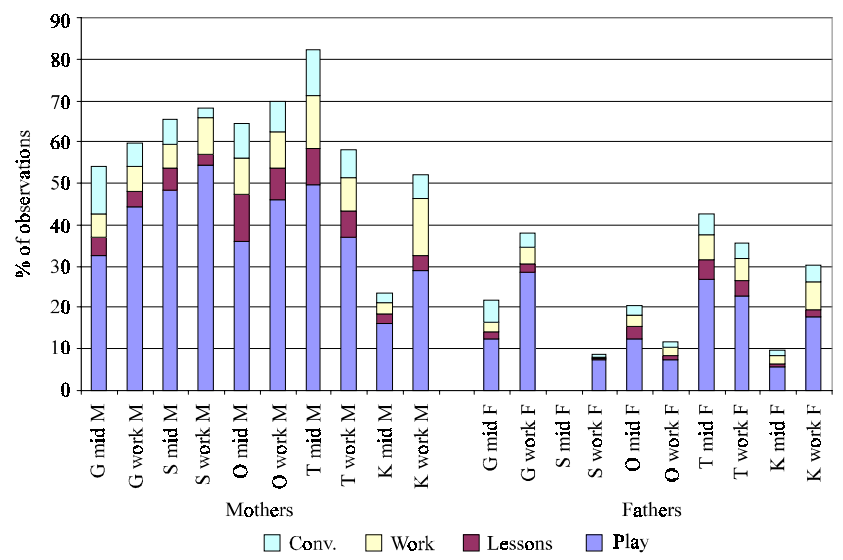

Figure 4. Activities in which children were involved when parents were in the setting (proportion of observations).

involved in work in Greensboro, Suwon, and (most clearly) in Kisumu. However in the two Eastern European cities middle class children were more likely to be observed engaged in work than were working class children.

Of greater interest in this paper, however, is the influence of parental presence on the types of activities in which the children were involved. As can be seen from Figure 3, mothers were far more likely to be in the same setting than were fathers, though there were wide variations among the groups. This was most apparent in the case of Suwon, where the middle class Korean fathers were almost never in the same setting as their children when observations were conducted, whereas the mothers were in those settings more than $70 \%$ of the observations. Fathers were more likely to be in the same setting as their children in Tartu and in Greensboro (particularly in the working class homes) than in the other cities.

We next wanted to know how these children spent their time when their mothers and fathers were with them. As displayed in Figure 4, when the mothers were available the proportions of the various types of activities in which the children were involved were similar to those of the children's days in general, regardless of the mothers' presence. Because the Suwon middle class fathers were so rarely in the setting their data have not been displayed. However, there tended to be a somewhat greater proportion of lessons, work, and conversation in all groups, and correspondingly a 
smaller proportion of play, when the mother was in the same setting. The fathers were with their children a smaller proportion of the time and therefore, not surprisingly, a smaller proportion of activities occurred while fathers were present. However, when expressed, as in Figure 5, as a proportion of the time that the parents were available to the children by being in the same setting with them, it is clear that the children were as likely to engage in these various activities when their mothers or their fathers were in the setting with them.

Figure 5 does indicate that in some cases (Suwon working class families and in Tartu) the children were slightly more likely to be engaged in play when their fathers were in the same setting than when their mothers were. However, the differences in extent of play were minimal, and from these data it would appear that fathers' presence, when compared to that of the mothers, has little impact on the type of activitiy in which the children are engaged.

Of more interest, however, is the extent to which the parents were actively engaged with their children in the various activities. Simply being present in the house but paying no attention to the child presumably means having less direct impact on the child's development. It is immediately apparent from examining Figure 6 that mothers were far more likely than were fathers to engage with their children in the various activities. It is also clear that both mothers and fathers were, relative to the extent to which the children engaged in these types of activities, less likely to participate in their children's play than they were to engage with them in lessons, work, or conversation. That is particularly true in the case of Kisumu.

These data provide a good sense of the extent to which mothers and fathers in these different groups actively engaged with their children over the course of a typical week. However, they are less effective at providing an understanding of the extent to which mothers and fathers engaged differentially with their children given their presence in the setting. In other words, although it is clear that fathers were far less likely than mothers to spend time in the company of their preschool-aged children, is it the case that they engaged in different types of activities with their children when they were present?

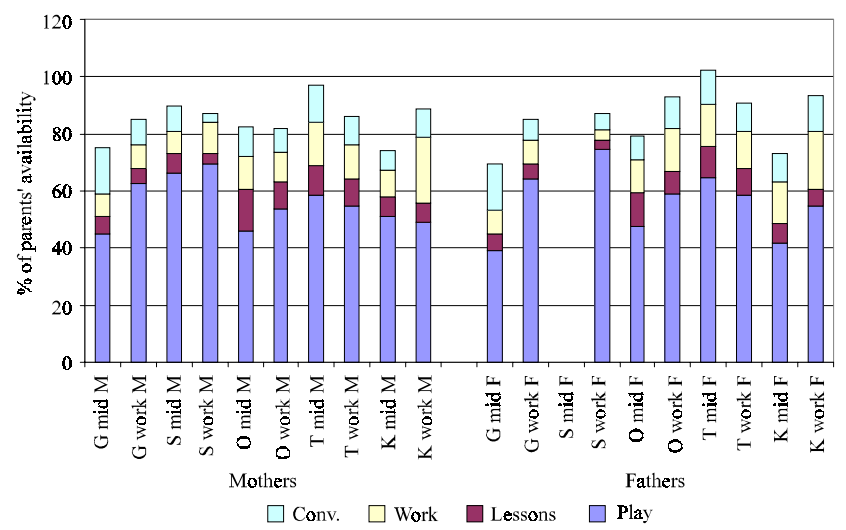

Figure 5. Activities in which children were involved when parents were in the setting (proportion of availability).

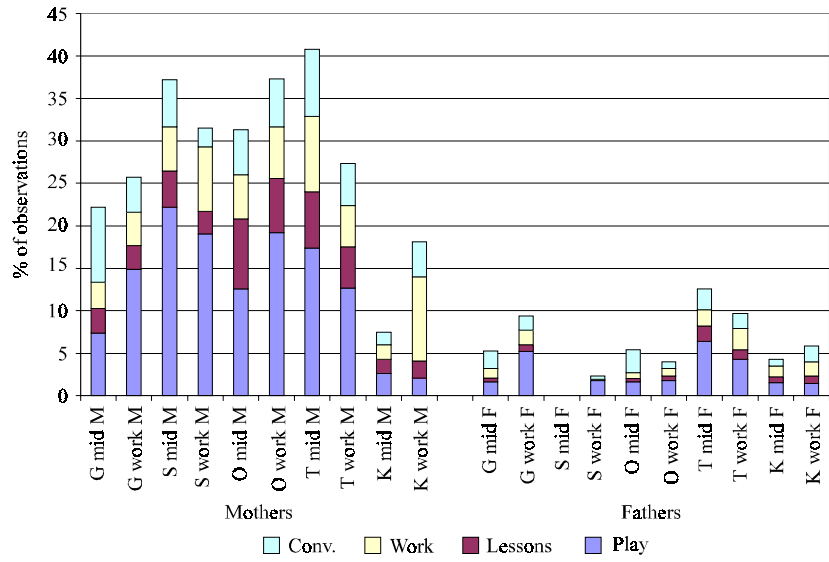

Figure 6. Activities in which parents were involved with their children (proportion of observations).

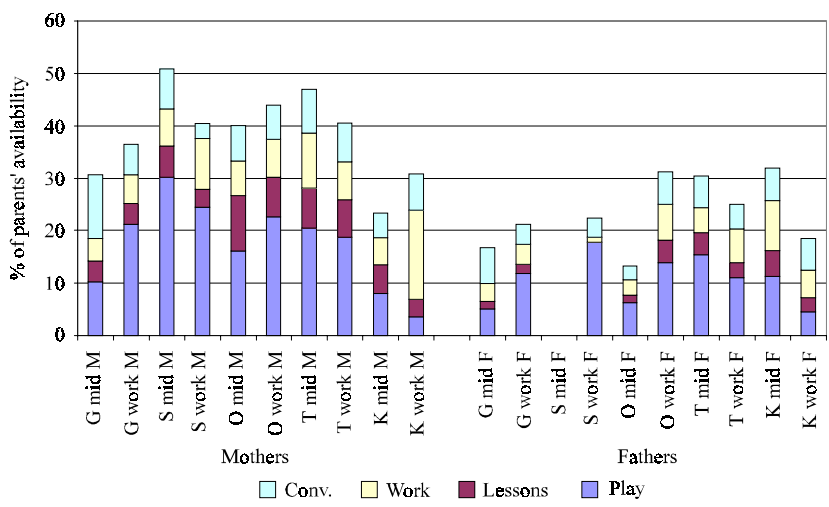

Figure 7. Activities in which parents were involved with their children (proportion of availability).

To answer this question, we examined mothers' and fathers' participation in activities with their children as a proportion of the extent to which they were present in the same setting as their children. As displayed in Figure 7, it is clear that in all cases except Kisumu, fathers were less likely than mothers to be involved in these activities with their children, even when expressed proportionally to their presence. Mothers, in other words, were more likely than fathers not only to be around their children, and to engage actively with them, but even when fathers were in the same setting as their children they were less likely to be involved in these activities.

\section{Discussion}

We presented these data in a purely descriptive fashion because they do not lend themselves to inferential statistics, which allow researchers to generalize from randomly-drawn samples to the populations from which the samples were drawn. These families were not members of randomly selected samples; however, they consisted of groups that were purposefully selected from specific communities. Our aim was to recruit all the families that met our requirements from those communities and, with the exception of the Suwon communities, we were quite successful. We were 
therefore dealing with small populations, rather than samples drawn from wider populations. At the population level, a difference is simply a difference, not one that need be inferred by reference to a test of statistical significance. We do not think that our data are not generalizable, however, and relate only to the specific groups we studied. The fact that in such different cultural contexts our findings were similar suggests that we may have observed a relatively widespread phenomenon.

As the literature has indicated, the fathers in this study were actively involved with their young children far less often than were the mothers. This was the case in societies as diverse as the United States, Kenya, Korea, Russia, and Estonia. In part this is because fathers were around their children much less frequently than were mothers - approximately half as much in Greensboro, Tartu, and Kisumu, and a good deal less than half in Suwon and Obninsk. Different reasons help explain why this should be the case. In Korea mothers of young children do not typically work outside the home, whereas fathers work long hours. Many of the Suwon fathers only returned from work after their children had gone to bed, and often worked away from home on the weekends. By contrast, prevailing cultural norms in both Russia and Estonia involve both mothers and fathers working outside the home. In the United States it has become increasingly common for mothers of young children to have a paying job if not a career, but economic considerations seem as likely to play a role as the belief that selffulfillment involves having a career, and about half of the mothers in the middle class Greensboro families did not work outside the home whereas all but one of the working class mothers did. In Russia, perhaps not surprisingly given the dramatic events of the final decade of the twentieth century and the resulting impoverishment of many families, several of the fathers of these children were no longer living at home either having left for good or having left to find employment elsewhere. The Kenyan middle class may be numerically far smaller than its US counterpart, but it was typically the case that the Kisumu middle class mothers did not work outside the home, whereas their working class counterparts did. As Lewis and Dessen (1998) argued, it is important to understand the impact on the family system of both parents working outside the home, when both parents are more likely to share (though by no means equally) responsibility for engaging with their children, compared to families in which the mother works only within the home.

The discrepancy in extent of parental availability to their children is wide enough to make it clear that mothers were still the main caregivers for their preschool-aged children in this diverse group of families. Nonetheless, when taking account of fathers' lesser availability (and expressing the data as a proportion of availability) it did not seem to be the case that children's engagement in activities was much changed by the fathers' presence. Irrespective of the parents' presence the proportion of activities in which the children were involved appeared quite similar when comparing activities in all settings with those in which they en- gaged when the mother was present and with those in which the father was present. In each group, the children were more likely to play than do anything else, even though the proportions of lessons, work, and conversation went up somewhat when the parents were available to them.

However, when we focused not simply on what the children were engaged in while the parents were available to them but on activities in which the parents were engaged as a partner, our data painted a striking picture. Mothers were far more likely than fathers to be engaged with their children, dramatically so in the case of Suwon and Obninsk. Again, given what we found in terms of the differential extent of availability, these data were not that surprising. What was surprising was that even when the data were expressed as a proportion of availability it was still the case that mothers were far more likely to be involved with their children than were fathers, with the single exception of the Kisumu middle class families. Moreover, it is clearly not the case that when fathers were with their young children they were more likely to play with them than were mothers. Although parents were more likely to be involved with their children in play and entertainment than in any other single activity, their involvement in play constituted 50\% or less of their total involvement. In other words, although we observed far more examples of play than lessons, work, or conversation parents were proportionally more likely to be involved in the latter activities.

There are some clear limitations to these data, as reported here. This is particularly the case with regard to our theoretical perspective. As presented here, the data are little more than reflective of a social address model of development, with variations in parental engagement in children's everyday activities (our measure of proximal processes) presented as an outcome measure, apparently "explained" by contextual (macrosystem) variation. In this paper we have only touched on the mechanisms that might allow us to draw the connections between context and outcome, such as the parents' child-rearing values and beliefs. We have also not presented any data about the ways in which the activities themselves start and how the children and/or the adults are drawn into those activities. From Bronfenbrenner's perspective individuals' directive beliefs and "developmentally-instigative characteristics" both need to be considered in a full PPCT model of development. We also have not discussed the individual variation in parents' availability to or involvement with their children. This variation is by no means great enough to account for the group differences, but personal characteristics and circumstances should not be ignored. Finally, and most problematic from a theoretical perspective, we have not discussed development itself, either by examining these children and their parents over time or by placing the study into its historical setting.

This article cannot be viewed, therefore, as a complete application of the theoretical perspective on which the research is based. Instead it should be viewed as filling out just one part of a broader picture. Data on the role that the children played in initiating the various activities in which 
they engaged have been presented elsewhere (Tudge, Doucet, et al., 1999), as have data on the parents' values and beliefs (Tudge, Hogan, Lee, et al., 1999; Tudge, Hogan, Snezhkova, Kulakova, \& Etz, 2000), and the extent to which parents engaged differentially with boys and girls (Hayes, 2000). We have not yet presented data on how parents and other social partners were drawn into activities by the children, how the children became involved, or variations in the ways in which mothers and fathers engaged with their children, but we have the opportunity to examine this from the videotapes filmed in each family. Moreover, we are not yet able to present complete data on the most interesting part of the work - the consequences of engaging in activities and engaging with social partners on subsequent development - but because the project is longitudinal we are in the process of gathering data from teachers and parents once the children have started to attend formal schooling.

Nonetheless, as one small piece in a larger puzzle, we have tried to focus on children's engagement in their everyday activities in conjunction with social partners who might be expected to play a significant role in their development. In particular, we have provided good observational evidence of the relatively limited role taken by fathers with their young children. Despite cultural (both societal and socioeconomic) variation in the patterns in virtually all groups, mothers were more likely than fathers to spend time in the company of their children. Moreover, even when fathers were present, they were less likely to be actively involved with their children than were mothers. In future publications we hope to be able to report the consequences of such variations in parental engagement. For now, however, we hope that we have helped to answer the call of Dessen and Lewis (1998) for more research on mothers' and fathers' engagement with their young children's everyday activities in a variety of cultural contexts.

\section{References}

Bronfenbrenner, U. (1989). Ecological systems theory. In R. Vasta (Ed.), Annals of child development (Vol. 6, pp. 187-249). Greenwich, CT: JAI Press.

Bronfenbrenner, U. (1993). The ecology of cognitive development: Research models and fugitive findings. In R. Wozniak $\&$ K. Fischer (Eds.), Development in context: Acting and thinking in specific environments (pp. 3-44). Hillsdale, NJ: Erlbaum.

Bronfenbrenner, U. (1995). Developmental ecology through space and time: A future perspective. In P. Moen, G. H. Elder, Jr. \& K. Lüscher (Eds.), Examining lives in context: Perspectives on the ecology of human development (pp. 619-647). Washington, DC: American Psychological Association.

Bronfenbrenner, U., \& Ceci, S. (1994). Nature-nurture reconceptualized in developmental perspective: A bioecological model. Psychological Review, 101, 568-586.

Bronfenbrenner, U., \& Morris, P. A. (1998). The ecology of developmental processes. In W. Damon (Series Ed.) \& R. M. Lerner (Vol. Ed.), Handbook of child psychology: Vol. 1. Theo- retical models of human development (5th ed., pp. 993-1028). New York: John Wiley.

Cole, M. (1985). The zone of proximal development: Where culture and cognition create each other. In J. V. Wertsch (Ed.), Culture, communication and cognition: Vygotskian perspectives (pp. 146-161). Cambridge: Cambridge University Press.

Cole, M. (1995). The supra-individual envelope of development: Activity and practice, situation and context. In W. Damon (Series Ed.), M. Goodnow, P. J. Miller, \& F. Kessel (Vol. Eds.), New directions for child development: Vol. 67. Cultural practices as contexts for development (pp. 105-118). San Francisco: Jossey-Bass.

Dessen, M. A., \& Lewis, C. (1998). Como estudar a família e o pai? [How can we understand families and fathers?]. Paidéia Cadernos de Psicologia e Educação [Paidéia: Journal of Psychology and Education], 14, 105-121.

Doherty, W. J., Kouneski, E. F., \& Erickson, M. F. (1998). Responsible fathering: An overview and conceptual framework. Journal of Marriage and the Family, 60, 277-292.

Draper, P., \& Harpending, H. (1987). Parent investment and the child's environment. In J. B. Lancaster, J. Altmann, A. S. Rossi, \& L. R. Sherrod (Eds.), Parenting across the life span: Biosocial dimensions (pp. 207-231). New York: Aldine.

Harkness, S., \& Super, C. M. (1995). Culture and parenting. In M. H. Bornstein (Ed.), Handbook of parenting: Vol 2. Biology and ecology of parenting (pp. 211-234). Mahwah, NJ: Erlbaum.

Hayes, S. W. (2000). Everyday interactions of North American preschoolers and their fathers: Gender, social class, and mother's influence. Unpublished master's thesis, The University of North Carolina at Greensboro.

Hollingshead, A. B. (1975). Four factor index of social status. Working paper, Yale University, New Haven, CT.

Howes, C., \& Clements, D. (1994). Adult socialization of children's play in child care. In H. Goelman \& E. V. Jacobs (Eds.), Children's play in child care settings (pp. 20-36). Albany, NY: State University of New York Press.

Howes, C., \& Tonyan, H. (1999). Peer relations. In L. Balter \& C. S. Tamis-LeMonda (Eds.), Child psychology: A handbook of contemporary issues (pp. 143-157). Philadelphia: Psychology Press.

Lamb, M. E. (Ed.). (1987). The father's role: Cross-cultural perspectives. Hillsdale, NJ: Erlbaum.

Lamb, M. E. (Ed.). (1997). The role of the father in child development. New York: John Wiley.

Lamb, M. E., Pleck, J. H., \& Levine, J. A. (1985). The role of the father in child development: The effects of increased paternal involvement. In B. Lahey \& A. Kazdin (Eds.), Advances in clinical child psychology (Vol. 8, pp. 229-266). New York: Plenum.

LeVine, R. A. (1988). Human parental care: Universal goals, cultural strategies, individual behavior. In W. Damon (Series Ed.), R. A. LeVine, P. M. Miller, \& M. M. West (Vol. Eds.), New directions for child development: Vol. 40. Parental behavior in diverse societies (pp. 3-12). San Francisco: Jossey-Bass.

LeVine, R. A. (1989). Cultural environments in child development. In W. Damon (Ed.), Child development today and tomorrow (pp. 52-68). San Francisco: Jossey-Bass. 
Lewis, C. (1997). Fathers and preschoolers. In M. Lamb (Ed.), The role of the father in child development (3rd ed., pp. 121142). New York: Wiley.

Lewis, C., \& Dessen, M. A. (1999). O pai no contexto familiar [Fathers in family life]. Psicologia: Teoria e Pesquisa, 15, 916.

Mackey, W. C. (1996). The American father: Biocultural and developmental aspects. New York: Plenum.

Marsiglio, W., Day, R. D., \& Lamb, M. E. (1997). Conceptualizing fatherhood: The social construction of paternal involvement. Paper presented at Theory Construction and Research Methods Pre-conference Workshop, National Council on Family Relations. Washington, D.C.

McBride, B. A., \& Mills, G. (1993). A comparison of mother and father involvement with their preschool age children. Early Childhood Research Quarterly, 8, 457-477.

Miller, P. J., \& Goodnow, J. J. (1995). Cultural practices: Toward an integration of culture and development. In W. Damon (Series Ed.), J. J. Goodnow, P. J. Miller, \& F. Kessel (Vol. Eds.), New directions for child development: Vol. 67. Cultural practices as contexts for development (pp. 5-16). San Francisco: Jossey-Bass.

Odero, D. A. (1998). Everyday activities and social partners of Luo children in an urban Kenyan setting: The roles of culture, class, and gender. Unpublished doctoral dissertation, the University of North Carolina at Greensboro.

Pleck, J. H. (1997). Paternal involvement: Levels, sources, and consequences. In M. E. Lamb (Ed.), The role of the father in child development (3rd ed., pp. 66-103). New York: Wiley.

Super, C. M., \& Harkness, S. (1986). The developmental niche: A conceptualization at the interface of child and culture. International Journal of Behavioral Development, 9, 545-569.

Taylor, R. J., Jackson, J. S., \& Chatters, L. M. (Eds.). (1997). Family life in Black America. Thousand Oaks, CA: Sage Publications.

Tobin, J. T., Wu, D. Y. H., \& Davidson, D. H. (1989). Preschool in 3 cultures. New Haven, CT: Yale University Press.

Tudge, J., Doucet, F., Odero, D., Tammeveski, P., Lee, S., Meltsas, M., \& Kulakova, N. (1999). Desenvolvimento infantil em contexto cultural: $\mathrm{O}$ impacto do engajamento de pré-escolares em atividades do cotidiano familiar [Child development in cultural context: The impact of preschoolers' engagement in everyday family activities]. Interfaces: Revista de Psicologia, 2, 23-32.

Tudge, J., Hogan, D., \& Etz, K. (1999). Using naturalistic observations as a window into children's everyday lives: An ecological approach. In F. M. Berardo (Series Ed.) \& C. Shehan (Vol. Ed.), Contemporary perspectives on family research: Vol. 1. Through the eyes of the child: Re-visioning children as active agents of family life (pp. 109-132). Stanford, CT: JAI Press.

Tudge, J., Hogan, D. M., Lee, S., Meltsas, M., Tammeveski, P., Kulakova, N., Snezhkova, I. A., \& Putnam, S. A. (1999). Cultural heterogeneity: Parental values and beliefs and their preschoolers' activities in the United States, South Korea, Russia, and Estonia. In A. Göncü (Ed.), Children's engagement in the world (pp. 62-96). New York: Cambridge University Press.
Tudge, J., Hogan, D., Snezhkova, I., Kulakova, N., \& Etz, K. (2000). Parents' childrearing values and beliefs in the United States and Russia: The impact of culture and social class. Infant and Child Development, 9, 105-121.

Tudge, J., \& Putnam, S. A. (1997). The everyday experiences of North American preschoolers in two cultural communities: A cross-disciplinary and cross-level analysis. In J. Tudge, M. Shanahan, \& J. Valsiner (Eds.), Comparisons in human development: Understanding time and context (pp. 252-281). New York: Cambridge University Press.

Tudge, J., Sidden, J., \& Putnam, S. A. (1990). The cultural ecology of young children: Coding manual. Unpublished manuscript, Greensboro, NC.

Volling B.L., \& Belsky, J. (1991). Multiple determinants of father involvement during infancy in dual earner and single-earner families. Journal of Marriage and the Family, 53, 461-474.

Vygotsky, L. S. (1987). The collected works of L. S. Vygotsky. In R. W. Rieber \& A. S. Carton (Eds.), Problems of general psychology (Vol. 1). New York: Plenum.

Vygotsky, L. S. (1997). The collected works of L. S. Vygotsky. In R. W. Rieber (Ed.), The history of the development of higher mental functions (Vol. 4). New York: Plenum.

Wakschlag, L. S., \& Chase-Landsdale, P. L. (1996). Not just "Ghosts in the Nursery": Contemporaneous intergenerational relationships and parenting in young African-American families. Child Development, 67, 2131-2147.

Weisner, T. S. (1984). Ecocultural niches of middle childhood: A cross-cultural perspective. In W. A. Collins (Ed.), Development during middle childhood. The years from six to twelve (pp. 335-369). Washington, DC: National Academy Press.

Weisner, T. S. (1987). Socialization for parenthood in sibling caretaking societies. In J. Lancaster, A. Rossi, \& J. Altman (Eds.), Parenting across the lifespan (pp. 237-270). New York: Aldine.

Whiting, B. B. (1963). Six cultures: Studies of child rearing. Cambridge: Harvard University Press.

Whiting, B. B., \& Edwards, C. P. (1988). Children of different worlds: The formation of social behavior. Cambridge: Harvard University Press.

Whiting, B. B., \& Whiting, J. W. M. (1975). Children of six cultures: A psycho-cultural analysis. Cambridge: Harvard University Press.

Youniss, J. (1994). Rearing children for society. In W. Damon (Series Ed.) \& J. Smetana (Vol. Ed.), New directions for child development, Vol. 66. Beliefs about parenting: Origins and developmental implications (pp. 37-50). San Francisco: JosseyBass. 